\title{
Progressive Pension Formula and Life Expectancy Heterogeneity
}

\author{
Keivan Diakite * and Pierre Devolder
}

Louvain Institute of Data Analysis and Modeling in Economics and Statistics, Université Catholique de Louvain, 1348 Ottignies-Louvain-la-Neuve, Belgium; pierre.devolder@uclouvain.be

* Correspondence: keivan.diakite@uclouvain.be

\begin{abstract}
An increasing number of empirical studies have shown a positive relationship between lifetime income and life expectancy at retirement. One's income during the active part of one's career translates into the amount of retirement benefits one might receive, leading to actuarial unfairness inside cohorts of retirees. In order to discuss unfairness and sustainability issues, the Belgium pension reform committee issued a proposal for a point system designed to be both sustainable and adequate. In this paper, we use a similar defined benefit framework in order to set out a compensation mechanism linked to life expectancy heterogeneity during the active part of the career, aiming to reduce unfairness once reaching retirement. This method is based on the progressivity of pension benefit formulae. We implement these ideas in a simple demographic context in order to capture the constraints related to the model.
\end{abstract}

Keywords: heterogeneity in life expectancy; pension scheme design; progressivity

Citation: Diakite, Keivan, and Pierre Devolder. 2021. Progressive Pension Formula and Life Expectancy Heterogeneity. Risks 9: 127. https:// doi.org/10.3390/risks9070127

Academic Editors: Mercedes Ayuso, Jorge Miguel Bravo, Edward Palmer and Robert Holzmann

Received: 29 April 2021

Accepted: 29 June 2021

Published: 3 July 2021

Publisher's Note: MDPI stays neutral with regard to jurisdictional claims in published maps and institutional affiliations.

Copyright: (c) 2021 by the authors. Licensee MDPI, Basel, Switzerland. This article is an open access article distributed under the terms and conditions of the Creative Commons Attribution (CC BY) license (https:// creativecommons.org/licenses/by/ $4.0 /)$.

\section{Introduction}

Many studies have observed different tendencies in the relationship between mortality and income. In a cross-country study covering 28 major western countries, (Neumayer and Plumper 2016) showed that income inequality before taxes and transfers was positively associated with inequality in the number of years lived. Unlike earlier times, the current increase in life expectancy of European nations seems to have been influenced by the development of the economy, as (Mackenbach and Looman 2013) showed.

This trend was also observed in Denmark in a 2008 study by (Brønnum-Hansen and Baadsgaard 2008), where their results showed that the gap in health expectancy between persons with low and high educational levels was increasing with startling constancy.

It has been shown that there are many factors influencing the differences in life expectancy, with income gained during the period of professional activity being one of them Kreiner et al. (2018); Kinge et al. (2019). On the same track, (Walczak et al. 2021) demonstrated that richer people live longer and that income has a considerably greater influence on life expectancy among men than among women. (Blanpain 2008) found that in France, people with better quality of life have higher life expectancy. For the period 2012-2016, among the wealthiest people, men had a life expectancy at birth of 84.4 years. In contrast, among the lowest $5 \%$ of people, men had a life expectancy of 71.7 years. The wealthiest men therefore live on average 13 years longer than the poorest (Blanpain 2016). Among women, this gap is smaller: the life expectancy at birth of women among the wealthiest $5 \%$ of people reaches 88.3 years, compared to 80.0 years among the lowest $5 \%$, i.e., 8 years apart.

Across societies, life expectancy is significantly linked to income Currie and Schwandt (2016a); Mackenbach et al. (2018). The relationship between a society's socioeconomic class and life expectancy is critical for measuring equality and assessing the risks and benefits of healthcare and social security policies, Snyder and Evans (2006); (Waldron 2007). The relationship between income and life expectancy is well documented, Currie and Schwandt (2016b); (Waldron 2007). Using tax data, (Chetty et al. 2016) calculated non parametric estimates of the relationship between income class and life expectancy. 
When ranked by socioeconomic level (SES), (Bosworth et al. 2016) discovered considerable death rate inequalities among elderly Americans, and these differences have expanded dramatically in recent years. It makes little difference whether we assess SES using education or midcareer earnings, though earnings are more directly linked to the income concept used to compute Social Security payments.

These studies demonstrate the influence of wealth disparity on life expectancy. When we apply the relationship between income and remaining life expectancy to public pension systems, we want to know what implications this relationship has on the contributionbenefit connection.

Public pension schemes transfer wealth over generations and, in some cases, among individuals. Individual pension benefits are not perfectly locked down by contributions, resulting in the latter sort of redistribution. Because individual pensions are given out as annuities regardless of life expectancy, the social security system transfers wealth from those with short lives to those with better life expectancies, according to (Borck 2007) and also (Belloni and Maccheroni 2013). When considering the life expectancy difference, Borck's paper may be viewed as an investigation of the impact of pension schemes' wealth transfer characteristics.

Pension systems may be progressive because lower-income persons often contribute less than higher-income people in order to gain a similar pension. Individuals with higher incomes, on the other hand, live longer. As a result, if the longer life expectancy outweighs the greater payments, the system may be regressive. There is evidence that actual pension plans can be regressive if individual variations in life expectancy are considered. E.g., Coronado et al. (2000); (Lefebvre 2007); Reil-Held (2000). (Mitchell and Zeldes 1996) explain that: "Despite its intent, the pension system is less progressive than it might seem, because there is a positive correlation between lifetime earnings and length of life". It is worth noting that this conclusion may be seen in both more Bismarckian systems, like the German system, and more Beveridgean systems, including the United States. More recently, (Economic Policy Committee 2020) stated that unless alternative sources of funding are found, a shrinking working-age population and an increasing number of retirees will place a double burden on future workers: greater contribution rates while working and smaller pensions when they retire. Furthermore, pension systems must ensure pension fairness and redistribution across income levels, as a shift in funding from social security contributions to taxation, as well as changes in progressivity rules, limits pension systems' redistributive capacity and raises questions about their fairness across income classes.

Heterogeneity in longevity and the underlying unfairness issue in pension schemes motivated (Holzmann et al. 2017) to propose redesigning the Notional Defined Contribution (NDC) scheme. Here, two promising design alternatives were briefly presented: individualized annuities and the multiple contribution model. In comparison to the current system, both conceptual models succeed in minimizing tax disparities.

Longevity heterogeneity and pension fairness have been studied quantitatively since (Ayuso et al. 2017); (Ayuso et al. 2021b); (Bravo et al. 2021). In order to measure the overall intensity of the transfer mechanism, profiles for tax/subsidy rates are computed from variances in life expectancy. (Culotta 2021) quatified this intensity in Italy between 1995 and 2019 by gender and region. This research not only provided an up-to-date picture of differences in lifespan among Italian regions, but it also calculated the implications of such disparities in terms of an implicit transfer of pension resources. His conclusion was that the conventional architecture of Italian public pension systems has to be changed to differentiate structural characteristics, such as the longevity factor used to calculate pension annuities. In principle, this would diminish the intensity of an implicit but persistent tax/subsidy mechanism. The choice of the socioeconomic factor to tag will be critical in this case. Nonetheless, in order to make completely transparent redistributive performances of public pension systems, a closer and updated monitoring of lifespan heterogeneity along important socioeconomic characteristics is required. 
Another approach would be taking into account the life expectancy differences directly in the pension formula, as (Breyer and Hupfeld 2008) did. In their work, they established the notion "distributive neutrality", which considers disparities in life expectancy based on income group, and then they empirically analyzed the relationship between annual wages and life expectancy among retirees and demonstrated how the mechanism that ties benefits to contributions would need to be adjusted to ensure distributive neutrality.

In this paper, we consider a defined benefit pension system as well as a stationary demographic framework in which agents are differentiated in terms of salary and life expectancy. To study the redistributive features of such a pension system, we consider the actuarial fairness ratio. This ratio for an agent is the discounted value of pension benefit over the agent's contributions. We introduce a progressive transformation of the pension formula that takes into account the life expectancy differential in order to satisfy two conditions: the sustainability condition of a PAYG scheme, and the actuarial fairness ratio equality condition for agents of different salary classes. The main contribution of this paper is to obtain the explicit form of this progressive transformation. We show in particular that under very special conditions (canonical case), the correction to apply in the pension formula is based on a simple ratio of life expectancies. However, in more general cases, especially when the discount rate used to estimate the level of fairness does not correspond to the actuarial return of the PAYG system, we use a more general transformation formula, based on two multiplicative factors: the ratio of annuities (longevity effect) and the ratio of aggregated salaries (salary effect). The study is structured as follows: In Section 2, we show the pension issue in our defined benefit framework as well as introducing the progressive concept, and we study the fairness properties in the general case. In Section 3, we apply our model to some specific cases before illustrating it with a simple numerical example. Section 4 allows us to conclude and discuss our results and highlight the questions that our study gives rise to.

\section{The Pension Unfairness Issue}

\subsection{Defined Benefits System Pension Calculation}

Let us imagine a career average re-evaluated earnings (CARE)-defined benefits scheme. Such system typically provides a retirement benefit based on a percentage of your average wages after taking inflation into account throughout the course of your participation in the scheme.

The pension benefit formula for a complete career at time $t$ is:

$$
P^{\left(t, x_{r}\right)}=\frac{\delta}{N} \cdot \sum_{x=x_{0}}^{x_{r}-1} S^{x} \prod_{i=1}^{x}\left(1+\gamma_{i}\right)^{x_{r}-i}
$$

where:

$x_{0}$ is the age of entry in the scheme and $x_{r}$ is the retirement age

$N$ is the normal length of contribution.

$P^{\left(t, x_{r}\right)}$ is the pension at retirement for a contribution period of $N=x_{r}-x_{0}$ years

$\gamma_{t}$ is the indexation rate for year $t$.

$\delta$ is the target replacement rate of the scheme.

$S^{x}$ is the individual salary taken into account at age $x$.

- At retirement

We assume that pensions in payment are adjusted each year according to the same coefficient as the indexation rate applied to the salary indexation of active workers:

$$
P^{(t, x)}=P^{(t-1, x)} \cdot\left(1+\gamma_{t}\right)
$$

- Actuarial Inequality tied to life expectancy disparity

Let us imagine a scheme with only two salary classes, low incomes and high incomes $\left(S_{1}^{x}<S_{2}^{x}\right)$, associated with low and high life expectancy at retirement $\left(e_{1}<e_{2}\right)$. 
In this framework, salaries are indexed with inflation rate $g$.

$$
S^{x+1}=S_{i}^{x} \cdot(1+g)
$$

The discount rate is equal to inflation.

In the DB framework, the pension formula at retirement is computed as a proportion of the salary:

$$
P_{j}=\delta \cdot S_{j}^{x_{r}}
$$

For each class $j$, the probability of surviving $t$ years at age $x$ is given by

$$
p_{j}(x ; x+t)
$$

The discount rate used in the PAYG system is equal to the inflation rate. This implies that the present value of benefits at retirement $B_{i}$ until death, denoted as $\omega$, is given by:

$$
\begin{aligned}
B_{j} & =\sum_{x=x_{r}}^{\omega} P_{j} \cdot p_{j}\left(x_{r} ; x\right) \cdot\left(\frac{1+g}{1+g}\right)^{\omega-x} \\
B_{j} & =P_{j} \cdot e_{j}
\end{aligned}
$$

where $e_{j}=\sum_{x=x_{r}}^{\omega} p_{j}\left(x_{r} ; x\right)$ is the remaining life expectancy.

The present value of contributions, with $\pi$ being the contribution rate is:

$$
\begin{aligned}
C_{j} & =\sum_{x=x_{0}}^{x_{r}-1} \pi \cdot S_{j}^{x} \cdot(1+g)^{x_{r}-x} \\
C_{j} & =N \cdot \pi \cdot S_{j}^{x_{r}}
\end{aligned}
$$

This leads to the the following results in term of the fairness ratio for low incomes:

$$
\frac{B_{1}}{C_{1}}=\frac{P_{1} \cdot e_{1}}{N \cdot \pi \cdot S_{1}}=\frac{\delta}{N \cdot \pi} \cdot e_{1}
$$

and for high incomes:

$$
\frac{B_{2}}{C_{2}}=\frac{P_{2} \cdot e_{2}}{N \cdot \pi \cdot S_{2}}=\frac{\delta}{N \cdot \pi} \cdot e_{2}
$$

The actuarial fairness ratio for an agent in this scheme is a proportion of the ratio between the remaining life expectancy at retirement of this agent and their contribution period.

When the two agents have contributed for the normal period, this ratio grows with life expectancy. This means that agents with higher life expectancy are expected to receive more benefits due to the fact that they receive their pension benefits for a longer period. The positive relationship of income with life expectancy leads us to think that people from low incomes are penalized for not living long enough.

This mechanism is a result of the proportionality of the pension benefit with the salary in the considered DB scheme. This conclusion is in line with the results of (Hachon 2009) regarding life expectancy inequalities and pension benefit unfairness.

The following section introduces the progressive transformation of the pension formula that takes into account life expectancy inequality in order to reach actuarial fairness for all salary classes. 


\section{Progressivity}

(Biggs et al. 2009) defined progressivity as "The degree to which benefits are higher relative to lifetime payroll contributions for lower contributors than for higher contributors". This is a translation of (Musgrave and Tun Thin 1948) approach regarding income tax.

The characterization of progressivity in pension benefits formulae is given in an OCED pension report (OCED 2011a). In this study, we show two pension systems operating according to a progressive formula: Switzerland and the USA.

\section{- USA}

The pension formula is progressive. Earning USD 895 a month gives a $90 \%$ replacement rate.

In 2018, the first 895 USD a month of relevant earnings attracts a $90 \%$ replacement rate. The income range is replaced at 32\% from 895 USD and 5397 USD. The 2018 average national pay index's upper and lower bounds are $20 \%$ and $118 \%$, respectively. Between the earlier cutoff and the earnings limitation, a replacement rate of $15 \%$ is applied.

$$
P= \begin{cases}0.9 \cdot S & \text { if } S<10,740 \\ 9666+0.32 \cdot(S-10,740) & \text { if } 10,740<S<64,764 \\ 20,725+0.15 \cdot(S-5397) & \text { if } S>64,764\end{cases}
$$

\section{- $\quad$ Switzerland}

The public earnings-related pension benefit is based on average lifetime earnings. Benefit payments include both superior and inferior limitations. The "two-branch" pension calculation benefits average earnings between these two levels. The pension computation tends to transfer income from rich to poor agents. Pension payouts ranged from $\mathrm{CHF}$ 14,100 to CHF 28,200 in 2016 with complete contributions. These figures correspond to $16 \%$ and $33 \%$ of mean worker wages, respectively. When the average income is CHF 84,600 , the maximum profit is $99 \%$ of the national economy average income. The formula for the complete contribution period is as follows:

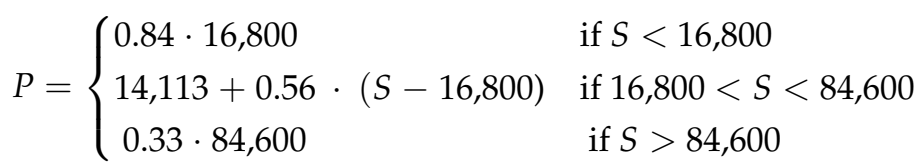

The existing system calibrates the progressive factors such that the pension benefit reaches certain thresholds such as quantiles of average salary; this approach only serves the accounting purpose of progressivity.

Our aim in the following part is to link the value of the progressive coefficients to the differences in life expectancy between salary classes in order to satisfy actuarial and accounting equilibrium.

\subsection{Progressive Pension Model and Fairness}

The defined benefit system is one of the most popular Pay-As-You-Go pension schemes, and it has been shown, under the premise of life expectancy inequalities related to income, that this system is unfair to low-income individuals.

Our aim is to use progressivity to calibrate the progressive coefficients with two conditions: actuarial fairness and Pay-As-You-Go equilibrium

\subsubsection{Model Hypothesis}

- The contribution period is denoted as $N$.

- $\quad$ There are $m$ working classes determined upon entry into the scheme characterized by their salary $\left(S_{1} ; . . ; S_{m}\right)$ and their proportion $\left(w_{1}, . ., w_{m}\right)$

- $\quad$ The age of entry in the scheme is denoted as $x_{0}$ and the age of retirement is denoted as $x_{r}$ 
- $\quad L(x, t)$ is the population function giving at date $t$ the size of the population of age $x$. We can write $L(x, t)=\sum_{i=1}^{m} L_{i}(x, t)$, where $L_{i}(x, t)=w_{i} \cdot L(x, t)$ is the size of the population aged $x$ at time $t$ in the class $i$.

- $\quad$ Let us initially consider a population in an absolutely stationary state. The population function is therefore independent of time.

- We ignore the effects of mortality before retirement. The population function at any age before retirement $x<x_{r}$ is given by:

$$
L(x, t)=L(x)=L
$$

- $\quad$ After retirement, we consider that each class has a different mortality evolution. If $p_{j}(x ; x+t)$ represents the probability of an agent aged $x$ and belonging to class $j$ surviving $t$ years, the population of class $j$ is given by:

$$
L_{j}(x ; t)=L_{j}\left(x_{r}, t\right) \cdot p_{j}\left(x_{r} ; x\right)
$$

- At any time $t$, let us imagine that the salary of an agent depends on their age $(x)$ and time $(t)$; this gives

$$
S_{j}^{(t ; x)}=S_{j}^{\left(0 ; x_{0}\right)} \cdot\left(1+s_{j}\right)^{x-x_{0}} \cdot(1+g)^{t}
$$

where $s_{j}$ is the career growth effect for the group $j$ salary and $g$ is the inflation effect depending on time $t$.

- The progressive salary transformation is given by:

$$
\begin{array}{r}
X\left(S_{2}\right)=\lambda_{1} \cdot S_{1}+\lambda_{2} \cdot\left(S_{2}-S_{1}\right) \\
X\left(S_{j}\right)=\lambda_{1} \cdot S_{1}+\sum_{i=2}^{j} \lambda_{i} \cdot\left(S_{i}-S_{i-1}\right)
\end{array}
$$

The general formula is:

$$
X(S)=\sum_{i=1}^{m} \lambda_{i} \cdot \max \left(\min \left(S, S_{i}\right)-S_{i-1} ; 0\right),
$$

where $\lambda_{1}, \ldots, \lambda_{m}$ are the progressive coefficients.

- After retirement, pension benefits are indexed with the same rate $\gamma$, and we have the following relationship at any age $x>x_{r}$ :

$$
P^{(t, x)}=P^{\left(t, x_{r}\right)} \cdot(1+\gamma)^{\left(x-x_{r}\right)}
$$

\subsubsection{Pension Formula}

We implemented the progressive mechanism in the pension formula, aiming to correct the underlying unfairness issue. In order to transform a DB system into a progressive one, we chose to transform the salary in the pension formula using salary bandwidths, and based on those thresholds, we apply the progressive coefficients.

We can write the salary transformation for any class $j$ as such with $S_{0}^{(t ; x)}=0$ :

$$
X\left(S_{j}^{(t ; x)}\right)=X_{j}^{(t ; x)}=\sum_{i=1}^{j} \lambda_{i} \cdot\left(S_{i}^{(t ; x)}-S_{i-1}^{(t ; x)}\right)
$$

For any $T>t, X_{j}^{(T ; x)}=X_{j}^{(t ; x)} \cdot(1+g)^{T-t}$ we obtain the pension at the time of retirement $T=N$ with: 


$$
\begin{aligned}
P_{j}^{\left(N, x_{r}\right)} & =\sum_{t=0}^{N-1} \frac{\delta}{N} \cdot X_{j}^{\left(t ; x_{0}+t\right)} \cdot(1+\gamma)^{N-t} \\
& =\frac{\delta}{N} \cdot \sum_{i=1}^{j} \lambda_{i} \sum_{t=0}^{N-1}\left(S_{i}^{\left(t ; x_{0}+t\right)}-S_{i-1}^{\left(t ; x_{0}+t\right)}\right) \cdot(1+\gamma)^{N-t}
\end{aligned}
$$

We also have

$$
\begin{aligned}
\widehat{S_{j}^{N}}(\gamma, g) & =\sum_{t=0}^{N-1}\left(S_{i}^{\left(t ; x_{0}+t\right)}\right) \cdot(1+\gamma)^{N-t} \\
& =S_{j}^{\left(0 ; x_{0}\right)} \cdot(1+\gamma) \cdot \frac{\left[(1+g) \cdot\left(1+s_{j}\right)\right]^{N}-(1+\gamma)^{N}}{(1+g) \cdot\left(1+s_{j}\right)-(1+\gamma)}
\end{aligned}
$$

The last term is the future value of a geometric annuity with growth $(1+g) \cdot\left(1+s_{j}\right)$ indexed at rate $1+\gamma$ over a period of time $N$. It is noted that

$$
G s_{j}^{(\gamma)}=(1+\gamma) \cdot \frac{\left[(1+g) \cdot\left(1+s_{j}\right)\right]^{N}-(1+\gamma)^{N}}{(1+g) \cdot\left(1+s_{j}\right)-(1+\gamma)}
$$

This leads to:

$$
P_{j}^{\left(N, x_{r}\right)}=\frac{\delta}{N} \cdot \sum_{i=1}^{j} \lambda_{i} \cdot\left(\widehat{S_{i}^{N}}(\gamma, g)-\widehat{S_{i-1}^{N}}(\gamma, g)\right)=\frac{\delta}{N} \cdot \widehat{X_{j}^{N}}(\gamma, g)
$$

with:

$$
\left.\widehat{X_{j}^{N}}(\gamma, g)=\sum_{i=1}^{j} \lambda_{i} \cdot \widehat{S_{i}^{N}}(\gamma, g)-\widehat{S_{i-1}^{N}}(\gamma, g)\right)
$$

Here, we give an explanation of the notations we have introduced so far:

- $\widehat{S_{j}^{N}}(\gamma, g)$ is the sum of all salaries throughout the career of an agent of class $j$ indexed at rate $\gamma$, with $g$ being the inflation effect.

- $\widehat{X_{j}^{N}}(\gamma, g)$ is the progressive transformation applied to the indexed sum of the salary.

\subsubsection{Pay-As-You-Go Equilibrium}

The number of active workers in the scheme is:

$$
\sum_{x=x_{0}}^{x_{r}-1} L(x, t)=\sum_{x=x_{0}}^{x_{r}-1} L=N \cdot L
$$

The total amount of contributions in the scheme for the agents of class $i$ is:

$$
\begin{aligned}
\sum_{x=x_{0}}^{x_{r}-1} L_{i}(x, t) \cdot \pi \cdot S_{i}^{(t, x)} & =\sum_{x=x_{0}}^{x_{r}-1} w_{i} \cdot L \cdot \pi \cdot S_{i}^{(t, x)} \\
& =w_{i} \cdot L \cdot \pi \cdot \sum_{x=x_{0}}^{x_{r}-1} S_{i}^{\left(t ; x_{0}\right)} \cdot\left(1+s_{i}\right)^{x-x_{0}} \\
& =w_{i} \cdot L \cdot \pi \cdot S_{i}^{\left(t ; x_{0}\right)} \cdot \sum_{x=x_{0}}^{x_{r}-1}\left(1+s_{i}\right)^{x-x_{0}}
\end{aligned}
$$

where $S_{i}^{\left(t ; x_{0}\right)} \cdot \sum_{x=x_{0}}^{x_{r}-1}\left(1+s_{i}\right)^{x-x_{0}}$ is the sum of all salaries of class $i$ from age $x_{0}$ to $x_{r-1}$. 
For all retired agents of class $i$, the total of the pension benefits paid is:

$$
\begin{aligned}
\sum_{x=x_{r}}^{\omega} L_{i}(x, t) P_{i}^{(t, x)} & =L \cdot w_{i} \cdot P_{i}^{\left(x_{r}\right)} \cdot \sum_{x=x_{r}}^{\omega} p_{i}\left(x_{r} ; x\right)\left(\frac{1+\gamma}{1+g}\right)^{\left(x-x_{r}\right)} \\
& =L \cdot w_{i} \cdot P_{i}^{\left(t, x_{r}\right)} \cdot a_{j}^{(\gamma, g)}
\end{aligned}
$$

where $a_{j}^{(\gamma, g)}=\sum_{x=x_{r}}^{\omega} p_{i}\left(x_{r} ; x\right)\left(\frac{1+\gamma}{1+g}\right)^{\left(x-x_{r}\right)}$ is a life annuity discounted with rate $\frac{(1+g)}{(1+\gamma)}$.

The pay-as-you-go equilibrium is characterized by the following relationship:

$$
\text { Contributions }^{t}=\text { Benefits }^{t}
$$

We are looking for the $\pi$ value that satisfies this equilibrium for any given replacement rate.

$$
\begin{array}{r}
\sum_{x=x_{0}}^{x_{r}-1} \sum_{i=1}^{m} L_{i}(x, t) \cdot \pi \cdot S_{i}^{(t, x)}=\sum_{x=x_{r}}^{\omega} \sum_{j=1}^{m} L_{j}(x, t) P_{j}^{(t, x)} \\
\pi \cdot \sum_{x=x_{0}}^{x_{r}-1} \sum_{i=1}^{m} w_{i} \cdot L \cdot S_{i}^{(t, x)}=\sum_{j=1}^{m} w_{j} \cdot L \cdot a_{j}^{(\gamma, g)} \frac{\delta}{N} \cdot \widehat{X_{j}}(\gamma, g) .
\end{array}
$$

We divide this expression by $L$.

$$
\begin{aligned}
& \pi \cdot \sum_{x=x_{0}}^{x_{r}-1} \sum_{i=1}^{m} w_{i} \cdot S_{i}^{(t, x)}=\frac{\delta}{N} \cdot \sum_{j=1}^{m} w_{j} \cdot \widehat{X}_{j}(\gamma, g) \cdot a_{j}^{(\gamma, g)} \\
& \pi \cdot \sum_{i=1}^{m} w_{i} \cdot \sum_{x=x_{0}}^{x_{r}-1} S_{i}^{(t, x)}=\frac{\delta}{N} \cdot \sum_{j=1}^{m} w_{j} \cdot \widehat{X}_{j}(\gamma, g) \cdot a_{j}^{(\gamma, g)}
\end{aligned}
$$

Here, we introduce $\bar{S}=\sum_{i=1}^{m} w_{i} \cdot \sum_{x=x_{0}}^{x_{r}-1} S_{i}^{(t, x)}$, being the average salary of all agents in the scheme.

This gives us the replacement rate and progressive factors for the sustainability conditions between the contribution rate.

$$
\delta=\frac{N \cdot \pi \cdot \bar{S}}{\sum_{i=1}^{m} \lambda_{1} w_{i} \cdot a_{i}^{(\gamma, g)} \cdot \widehat{S_{1}^{N}}(\gamma, g)+\sum_{i=2}^{m} \lambda_{i} \sum_{j=i}^{m} w_{j} \cdot a_{j}^{(\gamma, g)} \cdot\left(\widehat{S_{i}^{N}}(\gamma, g)-\widehat{S_{i-1}^{N}}(\gamma, g)\right)}
$$

The equilibrium is characterized by this equation for $\left(\lambda_{1} ; . . \lambda_{m} ; \delta\right)$ where $\delta>0$

$$
\pi=\frac{\delta \cdot \sum_{i=1}^{m} \lambda_{i} \cdot b_{i}}{N . \bar{S}}
$$

with $b_{j}=\sum_{j=i}^{m} w_{j} \cdot a_{j}^{(\gamma, g)} \cdot\left(\widehat{S_{i}^{N}}(\gamma, g)-\widehat{S_{i-1}^{N}}(\gamma, g)\right)$.

This relationship expresses the fact that for a given replacement rate $\delta$ and a vector of progressive factors $\lambda^{\prime}=\left(\lambda_{1} ; \ldots ; \lambda_{m}\right)$, the contribution rate that allows for the sustainability of the scheme is given by the previous relationship (13).

Using this, we implement our second criterion, namely actuarial fairness for every agent in order to find the value of the progressive factors $\left(\lambda_{1}, \ldots, \lambda_{m}\right)$.

\subsubsection{Inter-Class Fairness Conditions}

We reach inter-class fairness when the actuarial fairness ratio is the same for every agent, regardless of their salary class. 
The PAYG condition allowed us to find a value for the system target contribution rate. In order to calibrate the progressive coefficients, we need to solve the inter-class fairness conditions:

- $\quad$ Present value of contributions

The present value of contributions is computed with the agents discount factor $r$. It is not necessarily an actuarial rate of return, but rather a rate which expresses the perception that agents have about the evolution of their contributions over time.

$$
\begin{aligned}
C_{j}^{N} & =\sum_{t=0}^{N-1} \pi \cdot S_{j}^{\left(t ; x_{0}+t\right)} \cdot(1+r)^{N-t} \\
& =\sum_{t=0}^{N-1} \pi \cdot S_{j}^{\left(0 ; x_{0}\right)} \cdot(1+g)^{t} \cdot\left(1+s_{j}\right)^{t} \cdot(1+r)^{N-t} \\
C_{j}^{N} & =\pi \cdot S_{j}^{\left(0 ; x_{0}\right)} \cdot(1+r) \cdot \frac{\left[(1+g) \cdot\left(1+s_{j}\right)\right]^{N}-(1+r)^{N}}{(1+g) \cdot\left(1+s_{j}\right)-(1+r)}
\end{aligned}
$$

Using the geometric annuity form, we can write the present value of contributions as:

$$
C_{j}^{N}=\pi \cdot S_{j}^{\left(0 ; x_{0}\right)} \cdot G s_{j}^{(r)}=\pi \cdot \widehat{S_{j}^{N}}(r, g)
$$

- Present value of benefits

At the time of retirement $N$, the pension benefit for the class $j$ is $P_{j}^{\left(N, x_{r}\right)}$. The present value of benefits for the class $j$ is indexed with rate $1+\gamma$, which is computed with the survival probability $p_{j}$ for the class $j$ :

$$
\begin{aligned}
& B_{j}^{N}=\sum_{x=x_{r}}^{\omega} P_{j}^{\left(N, x_{r}\right)} \cdot p_{j}\left(x_{r} ; x\right) \cdot\left(\frac{1+\gamma}{1+r}\right)^{x-x_{r}} \\
& B_{j}^{N}=P_{j}^{\left(N, x_{r}\right)} \cdot a_{j}^{(\gamma, r)}
\end{aligned}
$$

where $a_{j}^{(\gamma, r)}=\sum_{x=x_{r}}^{\omega} p_{j}\left(x_{r} ; x\right) \cdot\left(\frac{1+\gamma}{1+r}\right)^{x-x_{r}}$ is the life annuity calculated for the population with survival probability $p_{j}(x ; x+t)^{1}$

- Fairness condition

We need to obtain the values of $\lambda$ for each career by solving the following inter-class fairness conditions:

$$
\frac{B_{1}^{N}}{C_{1}^{N}}=\ldots=\frac{B_{j}^{N}}{C_{j}^{N}}=\ldots=\frac{B_{m}^{N}}{C_{m}^{N}}
$$

This leads to the following system 


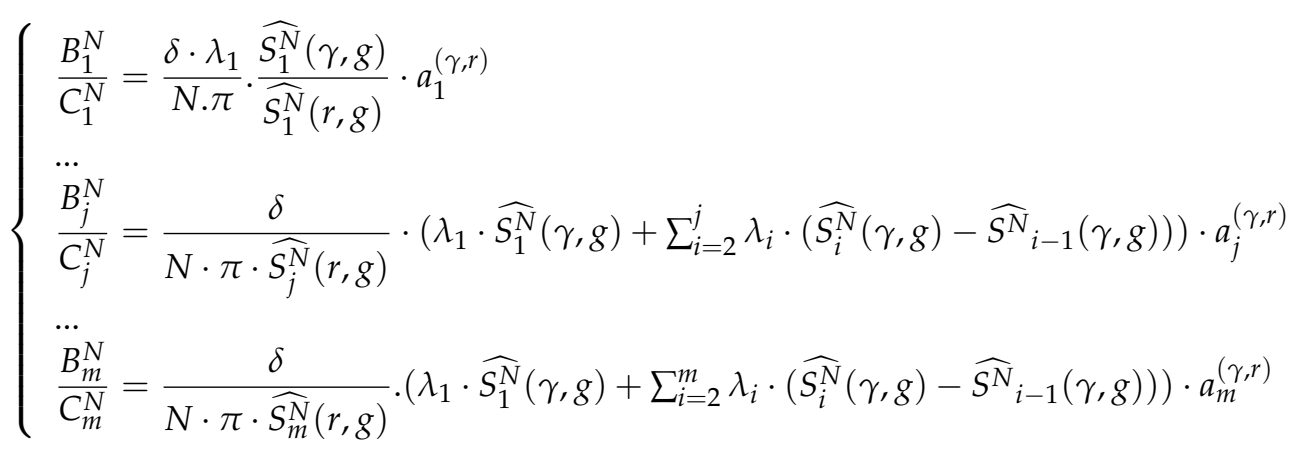

The solution is given by:

$$
\lambda^{\prime}=\left(\lambda_{1}, \ldots, \lambda_{m}\right)
$$

$\lambda$ is thus the vector of solution for our $(m-1)$ conditions. The coordinates are all a scalar times $\lambda_{1}$.

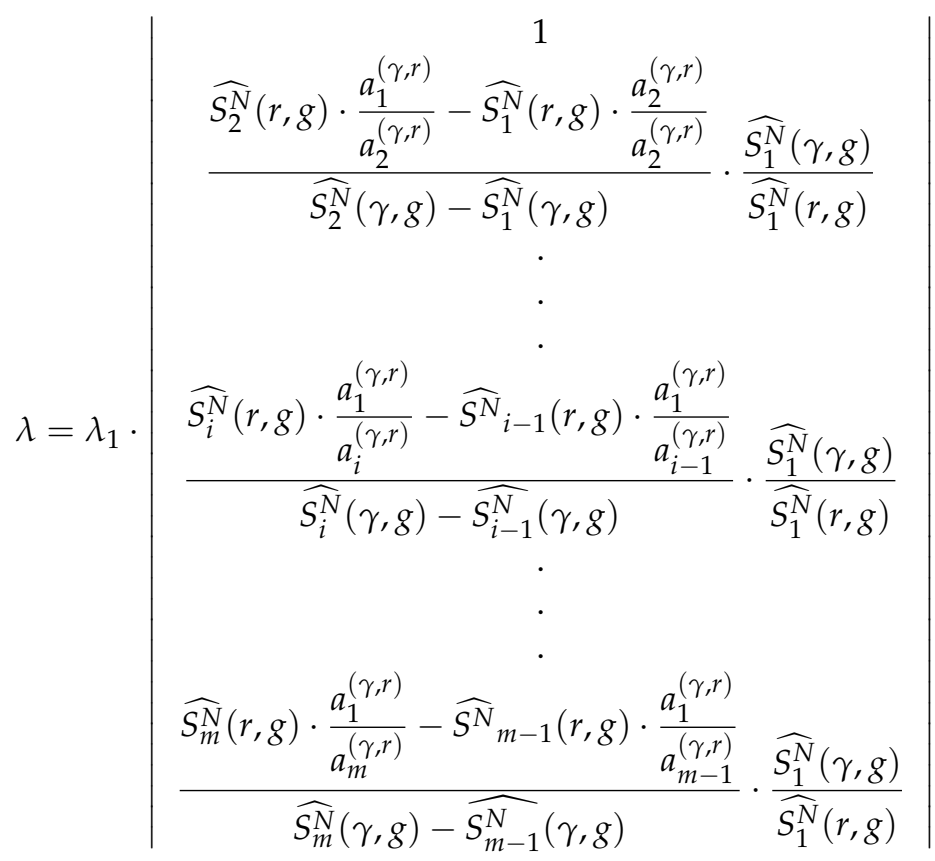

The progressive fair pension is then expressed as:

$$
P_{j}^{\left(N, x_{r}\right)}=\frac{\delta}{N} \cdot \widehat{X_{j}^{N}}=\frac{\delta}{N} \cdot \sum_{i=1}^{j} \lambda_{i} \cdot\left(\widehat{S_{i}^{N}}(\gamma, g)-\widehat{S_{i-1}^{N}}(\gamma, g)\right)
$$

We then use the expression of the progressive factors in the solution of the inter-class fairness condition in the pension formula; this allows us to reduce the telescopic sum in this way for any class $j>1$ :

$$
P_{j}^{\left(N, x_{r}\right)}=\delta \cdot \lambda_{1} \cdot \frac{\widehat{S_{1}^{N}}(\gamma, g)}{\widehat{S_{1}^{N}}(r, g)} \cdot \frac{\widehat{S_{j}^{N}}(r, g)}{N} \cdot \frac{a_{1}^{(\gamma, r)}}{a_{j}^{(\gamma, r)}}
$$

Here, we introduce

$$
\beta_{j}=\frac{\widehat{S_{j}^{N}}(r, g)}{\widehat{S_{j}^{N}}(\gamma, g)} \cdot \frac{\widehat{S_{1}^{N}}(\gamma, g)}{\widehat{S_{1}^{N}}(r, g)}
$$


being the correction term for the indexation of the classes. The fair pension then becomes:

$$
P_{j}^{\left(N, x_{r}\right)}=\delta \cdot \lambda_{1} \cdot \frac{\widehat{S_{j}^{N}}(\gamma, g)}{N} \cdot \beta_{j} \cdot \frac{a_{1}^{(\gamma, r)}}{a_{j}^{(\gamma, r)}}
$$

This quantity can be interpreted as a replacement rate multiplied by the average career salary with two corrections: the first one is an economic correction linked to the disparity between the evolution of the agent's salary during their career and the scheme indexation rate, and the second one is a correction tied to the mortality differential between the classes.

Proposition 1. For any couple $\left(\delta, \lambda_{1}\right)$ and any discount rate $r$, there is a vector $\lambda=\left(\lambda_{1} ; . . ; \lambda_{m}\right)$ satisfying at the same time the PAYG and inter-class fairness conditions given by (13) and (16).

The theoretical expression of the actuarial ratio is the same for every agent ${ }^{2}$.

$$
\frac{B_{j}}{C_{j}}=\frac{\delta \cdot \lambda_{1}}{N \cdot \pi} \cdot \widehat{\widehat{S_{1}^{N}}(\gamma, g)} \cdot \widehat{\widehat{S_{1}^{N}}(r, g)} \cdot a_{1}^{(\gamma, r)}
$$

This result demonstrates the fact the progressive fair pension makes it possible to obtain the same ratio of benefits to contributions for all classes. However, this ratio is not necessarily equal to one. In the following part, we explore the conditions regarding the discount rate in order for the system to be fair and reach equilibrium.

\section{Canonical Actuarial and Indexation Rates}

Aaron (1966) explained the relationship between the actuarial rate (equilibrium return) on PAYG social security and the income growth rate, as the sum of two rates: earnings growth per head and population growth rate.

In our framework, the canonical case will correspond to the two following conditions:

- The revaluation of pensions is consistent with the increase in salaries $(g=\gamma)$;

- The discount rate $r$ used to estimate the level of fairness is equal to the rate of return of the PAYG system. In the demographic stationary situation, this rate of return is equal to the rate of increase in the salaries $(g)$.

Therefore, the canonical case leads to: $r=g=\gamma$.

\subsection{Canonical Model}

We chose the canonical values of the discount factor and the indexation rate of the scheme. In a stationary demographic framework, they are equal. We compute here the progressivity coefficients in the canonical case.

- Pension formula and present values.

The sum of the salaries becomes:

$$
\widehat{S_{j}^{N}}=S_{j}^{\left(0 ; x_{0}\right)} \cdot \frac{1-s_{j}^{N}}{1-s_{j}}
$$

Thus, the pension Formula (9) transforms into:

$$
P_{j}^{N}=\frac{\delta}{N} \cdot \sum_{i=1}^{j} \lambda_{i} \cdot\left(\widehat{S_{i}^{N}}-\widehat{S_{i-1}^{N}}\right)=\frac{\delta}{N} \cdot \widehat{X_{j}^{N}}
$$


with:

$$
\widehat{X_{j}^{N}}=\sum_{i=1}^{j} \lambda_{i} \cdot\left(\widehat{S_{i}^{N}}-\widehat{S_{i-1}^{N}}\right)
$$

The present value of benefits at the time of retirement $N$ is:

$$
\begin{aligned}
B_{j}^{N} & =\sum_{x=x_{r}}^{\omega} P_{j}^{N} \cdot p_{j}\left(x_{r} ; x\right) \cdot\left(\frac{1+\gamma}{1+r}\right)^{x-x_{r}} \\
& =P_{j}^{N} \sum_{x=x_{r}}^{\omega} \cdot p_{j}\left(x_{r} ; x\right) \\
B_{j}^{N} & =P_{j}^{N} \cdot e_{j}
\end{aligned}
$$

The present value of contributions at the time of retirement $N$ is given by:

$$
\begin{gathered}
C_{j}^{N}=\sum_{t=0}^{N-1} \pi \cdot S_{j}^{\left(t ; x_{0}+t\right)} \cdot(1+r)^{N-t} \\
C_{j}^{N}=\pi \cdot \widehat{S_{j}^{N}}
\end{gathered}
$$

- $\quad$ PAYG equilibrium.

The PAYG equilibrium expression on the target replacement rate and contribution rate becomes independent of $(\gamma, g)$ and becomes

$$
\pi=\frac{\delta \cdot \sum_{i=1}^{m} w_{i} \cdot \widehat{X}_{i}^{N} \cdot e_{i}}{N . \bar{S}}
$$

- Inter-class fairness.

We express the actuarial fairness equality condition between the classes. This leads to the condition on the progressive factors:

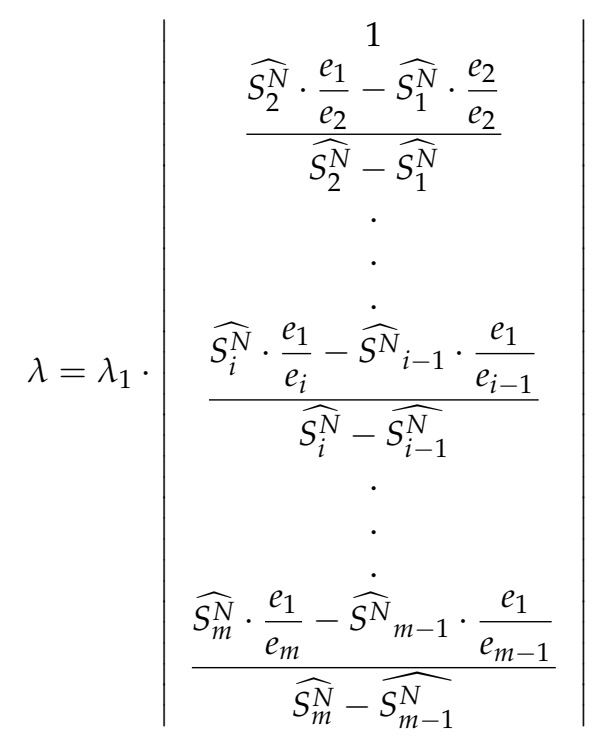

The progressive fair pension calculated with the progressive coefficients is thus:

$$
P_{j}^{N}=\frac{\delta}{N} \cdot \widehat{X_{j}^{N}}=\frac{\delta}{N} \cdot \sum_{i=1}^{j} \lambda_{i} \cdot\left(\widehat{S_{i}^{N}}-\widehat{S_{i-1}^{N}}\right)
$$


We compute the pension with the progressive factors obtained via the inter-class fairness condition:

$$
P_{j}^{N}=\delta \cdot \lambda_{1} \cdot \frac{\widehat{S_{j}^{N}}}{N} \cdot \frac{e_{1}}{e_{j}}
$$

In this case, since the discount rate and the indexation rate are the same, we notice that the fair pension has only one correction term, which is the mortality correction expressed as the ratio between two remaining life expectancies; the salary term has no effect with canonical rates:

$$
\beta_{j}=1
$$

Then, the actuarial ratio becomes, using (27) and (28):

$$
\begin{aligned}
\frac{B_{j}^{N}}{C_{j}} & =\frac{\delta . \lambda_{1} \cdot e_{1}}{N \cdot \pi} \\
& =\frac{\lambda_{1} \cdot e_{1} \cdot \bar{S}}{\sum_{i=1}^{m} w_{i} \cdot \widehat{X}_{i} \cdot e_{i}}
\end{aligned}
$$

As this sum is telescopic, we thus obtain:

$$
\sum_{i=1}^{m} w_{i} \cdot \widehat{X}_{i} \cdot e_{i}=\sum_{i=1}^{m} w_{i} \cdot \lambda_{1} \cdot S_{i} \cdot e_{1}=\lambda_{1} \cdot e_{1} \cdot \bar{S}
$$

Thus, with canonical rates, the system reaches perfect actuarial fairness for all of the classes:

$$
\frac{B_{j}^{N}}{C_{j}^{N}}=1
$$

\subsection{No Salary Indexation Model and Illustration} $s_{j}=0$,

We will consider here a special case of a canonical environment where $g=0$ and

- Salaries are constant during the career.

- There is no indexation.

- The annuity used to compute the present value of benefits is simply the life expectancy at retirement:

$$
\begin{aligned}
B_{j} & =\sum_{x=x_{r}}^{\omega} P_{j} \cdot p_{j}\left(x_{r} ; x\right) \\
& =P_{j} \sum_{x=x_{r}}^{\omega} \cdot p_{j}\left(x_{r} ; x\right) \\
B_{j} & =P_{j} \cdot e_{j}
\end{aligned}
$$

At any time $t$, the salary in a class $j$ is $S_{j}^{t}=S_{j}$.

For an individual in a salary class $j$, their pension at retirement for a complete career is computed as such:

$$
\begin{aligned}
P_{j} & =\sum_{t=1}^{N} \frac{\delta}{N} \cdot X_{j} \\
P_{j} & =\delta \cdot X_{j}
\end{aligned}
$$


The PAYG equilibrium becomes:

$$
\sum_{i=1}^{m} w_{i} \cdot P_{i}^{N} \cdot e_{i}=\sum_{i=1}^{m} w_{i} \cdot C_{i}^{N}
$$

This leads to the condition on the contribution rate:

$$
\pi=\frac{\delta \cdot \sum_{i=1}^{m} w_{i} \cdot X_{i} \cdot e_{i}}{N . \bar{S}}
$$

With the inter-class fairness, we have the following condition for the progressive factors for $j>1$ :

$$
\lambda_{j}=\lambda_{1} \cdot \frac{S_{j} \cdot \frac{e_{1}}{e_{j}}-S_{j-1} \cdot \frac{e_{1}}{e_{j-1}}}{S_{j}-S_{j-1}}
$$

The fair pension is given by:

$$
P_{i}=\delta \cdot \lambda_{1} \cdot S_{i} \cdot \frac{e_{1}}{e_{i}}
$$

This expression is very intuitive and underlines the fact that, in this particular situation, we can correct unfairness using the life expectancy ratio in the pension formula.

Numerical Illustration

Here, we used French data on the distribution of net monthly salaries in 2016 from “Tableaux de l'économie française Édition 2018 " 3 . We chose eight quantiles of salary to create our classes, and each salary is associated with a life expectancy at 65 . We assume that there is no salary indexation.

In our defined-benefit scheme, the target replacement rate is fixed: $\delta=0.8$. We use the conditions of (4.1) linking the progressive coefficients with salary level and life expectancy from Table 1 in order to generate our progressive coefficients:

Table 1. Life expectancy with salary level.

\begin{tabular}{ccc}
\hline Social Class & Salary & Life Expectancy (65) \\
\hline Class 1 & 1171 & 19.47 \\
Class 2 & 1288 & 20.36 \\
Class 3 & 1396 & 21.26 \\
Class 4 & 1512 & 22.18 \\
Class 5 & 1830 & 23.1 \\
Class 6 & 2073 & 24.03 \\
Class 7 & 2432 & 24.98 \\
Class 8 & 3149 & 25.93 \\
\hline
\end{tabular}

We use (30) and the values of the progressive factors in Table 2 to find the equilibrium contribution rate: $\pi=0.346$.

Table 2. Progressive coefficients generated with the Salary/life expectancy table.

\begin{tabular}{cccccccc}
\hline$\lambda_{1}$ & $\lambda_{2}$ & $\lambda_{3}$ & $\lambda_{4}$ & $\lambda_{5}$ & $\lambda_{6}$ & $\lambda_{7}$ & $\lambda_{8}$ \\
\hline 1.00 & 0.51 & 0.43 & 0.42 & 0.47 & 0.82 & 0.60 & 0.65 \\
\hline
\end{tabular}

If we apply the correction of those progressive factors on the salary thresholds in the pension formula, the inter-class fairness condition is respected, while the actuarial fairness ratio reaches 1 because there is no indexation. 


\section{Discussion}

Income during one's career and the remaining life expectancy at retirement are inextricably linked. In pension schemes, this correlation induces certain inequalities. The average life expectancy tends to increase with increasing income, meaning that high-status agents obtain more benefits relative to their contributions in most Bismarckian pension designs (Hachon 2009).

In many nations, income distributions are getting increasingly uneven. As mentioned before, mortality and lifespan inequalities have been widening in many, but not all, nations. While broadening income distributions appear to be an apparent explanation for growing Socioeconomic Status (SES) mortality disparities, most empirical research is unable to throw light on this issue because they measure income or education by quantiles, which do not represent broadening or narrowing of distributions. Our methodology for the agents classification also relies on quantiles income. Although secular trends in differential mortality are considerable, their impact on the length of time people get benefits is muted by the fact that low-SES individuals tend to claim Social Security at earlier ages, and highSES employees are more inclined to postpone retirement and benefit claiming. Differences in mortality throughout the earnings distribution negate part of the Social Security benefit formula's progressivity, but the pattern of lifetime benefits remains progressive (Bosworth et al. 2016).

This paper sought to introduce a progressive component in the pension formula of a defined-benefit scheme, offering a correction to the fairness linked to life expectancy inequalities in a stationary demographic framework. In comparison with (Breyer and Hupfeld 2008) and their "Distributive Neutrality" approach in relation to pension benefits, our method introduces an additional correction term, the mortality correction, which is quite similar. The progressive pension formula that we proposed used factors that are the solution of actuarial equilibria conditions on salary level thresholds that can be chosen. The main result is that under the absolute stationary hypothesis, fairness between the classes can be obtained for any discount rate.

Our contribution is based on a theoretical discussion of the redistributive features of pension systems when life expectancy is linked to salary levels. We expand on the sentence from (Mitchell and Zeldes 1996) that was mentioned in the beginning. PAYG DB pension systems are demonstrated to be less progressive than they appear to be. Furthermore, we demonstrate that, when the progressive pension formula is used, an equivalent redistribution of resources by wage distribution may be achieved.

Our progressive pension model links the pension formula to demographic and economical factors, with the immediate result being that the pension is reduced as life expectancy increases. This is an especially important issue for low-wage workers. As life expectancy rises, cutting their already inadequate payments could lead to a revival of oldage poverty. This link was studied in (OCED 2011b), where they demonstrated that there must be limits to tying benefit amounts to life expectancy. If benefit cuts force low-income workers to rely on social assistance and other safety-net programs in retirement, the savings from the life-expectancy link in public earnings-related benefits will be negated in part or entirely (notional accounts, defined-benefit or points). With private defined-contribution plans, it will mean more public spending. Parts of the pension system may have enhanced financial stability, but retirement income provision as a whole will not.

Our proposal introduces a modification of the benefit formula, it is vital to remember that modifying the retirement pension formula can have significant incentive consequences, which can affect resource allocation efficiency. In a dynamically efficient economy, every PAYG obligatory pension scheme imposes an implicit tax on labor supply since the present value of future retirement benefits is lesser than the matching payments. (Breyer and Hupfeld 2008) previously stated that increasing the retirement pension for poor workers and cutting it for rich workers will would boost (uncompensated) labor supply while reducing the tax burden. Then as result, the proposed revision of the retirement benefit formula's allocation impacts would, if anything, be beneficial. 
Pension age or career trajectory are usually a better option to tie life expectancy to than pension benefits, since the latter generates lower income in retirement, which raises pension adequacy and old age income inequality concerns. It is crucial to recall, that the usual work life is growing longer; expanding it is one way of reconciliing sustainability and adequacy of the pension system in the context of aging populations by re-balancing working and retirement times. Knowing ahead of time that longer life expectancy involves working longer to make appropriate retirement payouts creates significant motivation for people to postpone retirement. Furthermore, the level of retirement benefits may have an indirect effect on mortality, particularly among the lower income categories. Since lower pension is a process that influences mortality itself, the proposed increase in pension savings in favor of low-income agents may improve life span within those categories, weakening the empirical association.

The demographic framework we used, although very simple, was necessary to understand how the correction was possible. The absolute stationary hypothesis forces the use of a periodic mortality table. Period life expectancy measurements have two drawbacks: first, they do not account for the likelihood that people' socioeconomic characteristics develop over time, namely, because membership in a particular demographic subgroup may change over time, so may the corresponding mortality rates. Except for education, this is usually the true for any metric of socioeconomic level. Second, life expectancy does not take into account the fact that mortality rates fall with time and at varying rates for people in different socioeconomic groups. Recent empirical evidence (Ayuso et al. 2021b); (Bravo et al. 2021); (Ayuso et al. 2021a) show that, at retirement ages, most countries have a significant and systematic divergence in cohort and period life expectancy measures, resulting in significant ex-ante tax/subsidies from generations to come to present generation and, as a result, an unjust actuarial relationship between contributions and pension benefits. In addition, this affects labor supply decisions, resulting in macroeconomic inefficiencies, and wrongly communicates solvency expectations, delaying pension changes. We are considering creating an extension of the model with a stochastic model of the effect of mortality and dynamic economic conditions on salaries and discount rates as well as including incomplete contribution periods.

Author Contributions: The original draft of this article has been written by K.D. under P.D. supervision. The results, conclusions and main contributions of this article were discussed and agreed by the two authors. All authors have read and agreed to the published version of the manuscript.

Funding: K.Diakite was financially supported by the convention ARC No. 18-23-088 P.Devolder did not receive support from any organization for the submitted paper.

Institutional Review Board Statement: Not applicable.

Informed Consent Statement: Not applicable.

Conflicts of Interest: We declare that there is no conflict of interest.

\section{Abbreviations}

The following abbreviations are used in this manuscript:

PAYG Pay-As-You-Go

DB Defined Benefits

NDC Notional Defined Contribution 


\section{Appendix A}

Here is displayed the details for the theoretical expression of the Actuarial fairness ratio (20):

$$
\begin{aligned}
\frac{B_{j}^{N}}{C_{j}^{N}}= & \frac{P_{j}^{\left(N ; x_{r}\right)} \cdot a_{j}^{(\gamma ; r)}}{\pi \cdot \widehat{S_{j}^{N}}(r, g)} \\
& =\frac{\delta \cdot \lambda_{1} \cdot \frac{\widehat{S_{1}^{N}}(\gamma, g)}{\widehat{S_{1}^{N}}(r, g)} \cdot \frac{\widehat{S_{j}^{N}}(r, g)}{N} \cdot \frac{a_{1}^{(\gamma, r)}}{a_{j}^{(\gamma, r)}} \cdots a_{j}^{(\gamma ; r)}}{\pi \cdot \widehat{S_{j}^{N}}(r, g)} \\
& =\frac{\delta}{N \cdot \pi} \cdot \frac{\widehat{S_{1}^{N}}(\gamma, g)}{\widehat{S_{1}^{N}}(r, g)} \cdot \lambda_{1} \cdot a_{1}^{(\gamma, r)}
\end{aligned}
$$

This expression can be developed further to prove that the ratio is not at equilibrium. Using the Formula (13) of the contribution rate, it comes:

$$
\frac{B_{j}^{N}}{C_{j}^{N}}=\frac{\bar{S}}{\sum_{i=1}^{m} \lambda_{i} \cdot b_{i}} \cdot \frac{\widehat{S_{1}^{N}}(\gamma, g)}{\widehat{S_{1}^{N}}(r, g)} \cdot \lambda_{1} \cdot a_{1}^{(\gamma, r)}
$$

Then, we need to use the solution for our progressive factors in the telescopic sum; this gives:

$$
\begin{aligned}
\frac{B_{j}^{N}}{C_{j}^{N}}=\frac{\sum_{i=1}^{m} w_{i} \cdot \sum_{x=x_{0}}^{x_{r}-1} S_{i}^{(t, x)}}{\lambda_{1} \cdot \frac{\widehat{S_{1}^{N}}(\gamma, g)}{\widehat{S_{1}^{N}}(r, g)} \cdot \sum_{i=1}^{m} w_{i} \cdot \widehat{S_{i}^{N}}(r, g) \cdot \frac{\widehat{a_{i}^{(\gamma, g)}}}{a_{i}^{(\gamma, r)}} \cdot \frac{\widehat{S_{1}^{N}}(\gamma, g)}{\widehat{S_{1}^{N}}(r, g)} \cdot \lambda_{1} \cdot a_{1}^{(\gamma, r)}} \\
\frac{B_{j}^{N}}{C_{j}^{N}}=\frac{\sum_{i=1}^{m} w_{i} \cdot \sum_{x=x_{0}}^{x_{r}-1} S_{i}^{(t, x)}}{\sum_{i=1}^{m} w_{i} \cdot \widehat{S_{i}^{N}}(r, g) \cdot \frac{a_{i}^{(\gamma, g)}}{a_{i}^{(\gamma, r)}}}
\end{aligned}
$$

In order for this ratio to reach equilibrium we need:

$$
\sum_{i=1}^{m} w_{i} \cdot \sum_{x=x_{0}}^{x_{r}-1} S_{i}^{(t, x)}=\sum_{i=1}^{m} w_{i} \cdot \widehat{S_{i}^{N}}(r, g) \cdot \frac{a_{i}^{(\gamma, g)}}{a_{i}^{(\gamma, r)}}
$$

If $r \neq g$ and the actuarial fairness ratio does not reach equilibrium.

\section{Notes}

$1 \quad$ In particular when $\gamma=r, a_{j}^{(\gamma, r)}=e_{j}$.

2 See Appendix A for proof.

3 https:/ / www.insee.fr/fr/statistiques/3303417? sommaire=3353488 (accessed on 30 June 2021).

\section{References}

Aaron, Henry. 1966. The Social Insurance Paradox. Canadian Journal of Economics and Political Science 32: 371-74. [CrossRef] Ayuso, Mercedes, Jorge Miguel Bravo, and Robert Holzmann. 2017. On the Heterogeneity in Longevity among Socioeconomic Groups. Global Journal of Human Social Science Research 17: 33-58.

Ayuso, Mercedes, Jorge Miguel Bravo, and Robert Holzmann. 2021a. Getting Life Expectancy Estimates Right for Pension Policy: Period versus Cohort Approach. Journal of Pension Economics and Finance 20: 212-31. [CrossRef]

Ayuso, Mercedes, Jorge Miguel Bravo, Robert Holzmann, and Edward Palmer. 2021b. Automatic indexation of pension age to life expectancy: When policy design matters. Risks 9: 96. [CrossRef] 
Belloni, Michelle, and Carlo Maccheroni. 2013. Actuarial Fairness When Longevity Increases: An Evaluation of the Italian Pension System. The Geneva Papers on Risk and Insurance-Issues and Practice 38: 638-74. [CrossRef]

Biggs, Andrew, Mark Sarney, and Christopher R. Tamborini. 2009. A Progressivity Index for Social Security. Social Security Office of Retirement and Disability Policy. Available online: https:/ / papers.ssrn.com/sol3/papers.cfm?abstract_id=1339904 (accessed on 30 June 2021).

Blanpain, Nathalie. 2008. Tables de mortalité par niveau de vie. Insee Résultats. Available online: https://www.insee.fr/fr/statistiques/ 3311425 (accessed on 30 June 2021).

Blanpain, Nathalie. 2016. L'espérance de vie par Niveau de vie-Méthode et Principaux Résultats. Insee Report F1801. Available online: http:/ / www.epsilon.insee.fr/jspui/bitstream/1/71153/1/f1801.pdf (accessed on 30 June 2021).

Borck, Rainald. 2007. On the Choice of Public Pensions when Income and Life Expectancy are Correlated. Journal of Public Economic Theory 9: 711-25. [CrossRef]

Bosworth, Barry, Gary Burtless, and Kan Zhang. 2016. Later Retirement, Inequality in Old Age, and the Growing Gap in Longevity between Rich and Poor. Washington: The Brookings Institution.

Bravo, Jorge Miguel, Michelle Ayuso, Robert Holzmann, and Edward Palmer. 2021. Addressing the Life Expectancy Gap in Pension Policy. Insurance: Mathematics and Economics 99: 200-21.

Breyer, Friedrich, and Stefan Hupfeld. 2008. Fairness of Public Pensions and Old-Age Poverty. Discussion Papers of DIW Berlin 817, DIW Berlin. Berlin: German Institute for Economic Research.

Brønnum-Hansen, Henrik, and Mikkel Baadsgaard. 2008. Increase in social inequality in health expectancy in Denmark. Scandinavian Journal of Public Health 36: 44-51. [CrossRef] [PubMed]

Chetty, Raj, Michael Stepner, and Sarah Abraham. 2016. The association between income and life expectancy in the United States, 2001-2014. Journal of the American Medical Association 315: 1750-66. [CrossRef]

Coronado, Julia Lynn, Don Fullerton, and Thomas Glass. 2000. The Progressivity of Social Security. NBER Working Paper 7520. Available online: https: / / www.nber.org/papers/w7520 (accessed on 30 June 2021).

Culotta, Fabrizio. 2021. Life Expectancy Heterogeneity and Pension Fairness: An Italian North-South Divide. Risks 9: 57. [CrossRef]

Currie, Janet, and Hannes Schwandt. 2016a. Inequality in mortality decreased among the young while increasing for older adults, 1990-2010. Science 352: 708-12. [CrossRef] [PubMed]

Currie, Janet, and Hannes Schwandt. 2016b. Mortality inequality: The good news from a county-level approach. Journal of Economic Perspectives 30: 29-52. [CrossRef]

European Economic Policy Committee. 2020. Joint Paper on Pensions 2019, Ref. Ares(2020)393902-22/01/2020. Brussels: European Economic Policy Committee.

Hachon, Christian. 2009. Who Really Benefits from Pension Systems? When Life Expectancy Matters. Revue D'économie Politique 119: 613-32. [CrossRef]

Holzmann, Robert, Alonso-García Jennifer, Labit-Hardy Heloise, and Andres M. Villegas. 2017. NDC Schemes and Heterogeneity in Longevity: Proposals for Redesign. IZA Discussion Papers 11193. Bonn: Institute of Labor Economics (IZA).

Kinge, Jonas Minet, Jørgen Heibø Modalsli, Simon Øverland, Håkon Kristian Gjessing, Mette Christophersen Tollånes, Ann Kristin Knudsen, Vegard Skirbekk, Bjørn Heine Strand, Siri Eldevik Håberg, and Stein Emil Vollset. 2019. Association of Household Income with Life Expectancy and Cause-Specific Mortality in Norway, 2005-2015. JAMA 321: 1916-23. [CrossRef] [PubMed]

Kreiner, Claus T., Torben H. Nielsen, and Benjamin L. Serena. 2018. Role of Income Mobility for the Measurement of Inequality in Life Expectancy. Proceedings of the National Academy of Sciences 115: 11754-59. [CrossRef] [PubMed]

Lefebvre, Mathieu. 2007. The Redistributive Effects of Pension Systems in Europe: A Survey of Evidence. LIS Working papers 457. Luxembourg: LIS Cross-National Data Center in Luxembourg.

Mackenbach, Johan, and Caspar Wn Looman. 2013. Life expectancy and national income in Europe, 1900-2008: An update of Preston's analysis. International Journal of Epidemiology 4: 1100-10. [CrossRef]

Mackenbach, Johan, José Rubio Valverde, Barbara Artnik, Matthias Bopp, and Henrik Brøn. 2018. Trends in health inequalities in 27 European countries. Proceedings of the National Academy of Sciences 115: 6440-45. [CrossRef] [PubMed]

Mitchell, Olivia, and Stephen Zeldes. 1996. Social Security Privatization: A Structure for Analysis. American Economic Review 86: 363-67.

Musgrave, Richard, and Tun Thin. 1948. Income Tax Progression, 1929-1948. Journal of Political Economy 56: 498. [CrossRef]

Neumayer, Eric, and Thomas Plumper. 2016. Inequalities of Income and Inequalities of Longevity: A Cross-Country Study. American Journal of Public Health 106: 160-65. [CrossRef]

OCDE. 2011a. Progressivity of Pension Benefit Formulae. In Pensions at a Glance 2011: Retirement-income Systems in OECD and G20 Countries. Paris: Éditions OCDE.

OCDE. 2011b. Linking Pensions to Life Expectancy. In Pensions at a Glance 2011: Retirement-Income Systems in OECD and G20 Countries. Paris: Éditions OCDE.

Reil-Held, Anette. 2000. Einkommen und Sterblichkeit in Deutschland: Leben Reiche Langer? Discussion paper 00-14, SFB 504. Mannheim: SFB.

Snyder, Stephen E., and William N. Evans. 2006. The effect of income on mortality: Evidence from the social security Notch. The Review of Economics and Statistics 88: 482-95. [CrossRef] 
Walczak, Damian, Jacek Wantoch-Rekowski, and Robert Marczak. 2021. Impact of Income on Life Expectancy: A Challenge for the Pension Policy. Risks 9: 65. [CrossRef]

Waldron, Hilary. 2007. Trends in mortality differentials and life expectancy for male Social Security-covered workers, by socioeconomic status. Social Security Bulletin 67: 1-28. [PubMed] 